\title{
Saúde e Doença no Início do Século XXI: Entre a Experiência Privada e a Esfera Pública ${ }^{1}$
}

CLAUDINE HERZLICH ${ }^{2}$

Sabe-se que a doença é ao mesmo tempo a mais individual e a mais social das coisas e que ela pertence simultaneamente ao domínio privado e ao espaço público. Este artigo interroga a maneira pela qual as Ciências Sociais analisam a experiência privada e pessoal da doença, cujo impacto no espaço público foi por elas discutido.

Palavras-chave: Experiência da doença; narrativa; indivíduo; sociedade; sociologia da saúde; saúde coletiva. 
Segundo o antropólogo francês Marc Augé (1984), "o grande paradoxo da experiência da doença é que ela é tanto a mais individual quanto a mais social das coisas". É também difícil discernir se saúde e doença pertencem ao domínio privado ou ao público. Os laços entre esses dois domínios não são imutáveis e, no campo da saúde e da doença, passaram por transformações freqüentes. No entanto, o corpo ainda pertence ao domínio privado. Embora a era em que as tradições religiosas faziam do corpo um tabu seja agora um passado distante, as sensações do corpo são ainda assuntos da intimidade, envolvendo até mesmo sigilo e rituais individuais cotidianos. Prestar atenção a estados corporais é uma atividade que diz respeito a relacionamentos fundamentais: é a família que ainda está profundamente implicada na preservação da saúde e em seus cuidados. Além disso, a saúde e a doença afetam vários aspectos da vida privada, em especial o amor e a sexualidade. Sobre a epidemia de Aids na África, van Nieberk (2002) afirmou que um dos seus efeitos foi "a brutalização da própria intimidade". Em sociedades com condições de vida precárias, a sexualidade continua a ser

\begin{abstract}
"uma das poucas avenidas de intimidade e de um concomitante senso de valor próprio e dignidade [...] Isso é assim até a Aids entrar em cena. Agora [...] um desastre não só está à espreita na esfera pública onde [...] se está quase predisposto a aguardá-lo, mas na esfera remanescente onde se poderia ter esperado manter alguma medida de controle e dignidade: a esfera do privado e do íntimo."
\end{abstract}

Não podemos falar de corpos, doença e saúde sem relacioná-los ao domínio público. A história da saúde é também a história dos países e cidades, do trabalho, das guerras e das viagens. Historiadores e sociólogos há muito tempo vêm analisando instituições assistenciais e políticas de saúde, determinando a evolução das epidemias e descrevendo as principais fases em "saúde coletiva". A maioria de nós pensava que se estava expondo uma tendência irreversível. À medida que o Estado de Bem-estar Social foi tomando forma, a saúde se tornou um tema político; e o "homem doente" desapareceria sob o exame atento da ciência. Em conseqüência, por um longo período, negligenciamos olhar para a saúde e a doença como experiências privadas e pessoais.

Contudo, desde então, muitos estudos têm abordado esse aspecto privado e examinado as narrativas em "primeira pessoa" dos doentes ou de pessoas próximas a eles. Porém, como é freqüente, a pesquisa está seguindo 
uma tendência da sociedade. Experiências individuais relativas à saúde e à doença não têm sido relatadas apenas em publicações científicas. Os pacientes estão se manifestando e usando suas experiências como argumentos a serem considerados na elaboração de políticas de saúde. Gostaria de analisar como nossas disciplinas acadêmicas vieram a se interessar pela experiência privada e pessoal da saúde e da doença, bem como a lidar com sua presença, ou ausência, no espaço público.

O caso da sociologia é exemplar. Com a percepção crescente de uma expansão da medicina nunca antes vista, os sociólogos começaram a trabalhar no campo da saúde nas décadas posteriores à Segunda Guerra Mundial. O assim chamado "modelo biomédico" adquiriu legitimidade inconteste como explicação e abordagem das doenças. Propondo questões sobre isso, Talcott Parsons (1951) pesquisou os significados sociais da saúde e investigou o papel da medicina não apenas como um conjunto de técnicas, mas também como um meio de controle e regulação social. Seguindo seu caminho, os sociólogos não analisaram a saúde e a doença como realidades privadas ou públicas; porém, ao contrário, consideraram-nas fenômenos definidos por "profissionais" e ao encargo da medicina e dos médicos. Durante uma primeira fase nesse campo de pesquisa, os sociólogos consideraram as doenças como um "papel social" e os pacientes como consumidores de cuidados de saúde que seguem as prescrições dos médicos.

Até que, durante os anos 1970, surgiu uma visão mais crítica. Cientistas sociais criticaram a crescente "medicalização" e o "controle social" que a medicina vinha exercendo sobre os corpos. Por detrás da medicina estava o Estado, impondo às pessoas e à saúde delas metas normativas. Em consonância com as idéias de Foucault, Armstrong (1995) criticou a instauração da "vigilância médica", que estava transformando não só a experiência com a doença e a atenção aos corpos, mas também as percepções da identidade. Nos primeiros anos em que essa visão crítica da medicina e do Estado veio tomando forma, os sociólogos mencionavam principalmente as experiências individuais para acusar e lamentar que a medicina estivesse nos impedindo de ouvir a autêntica "voz do paciente".

O espírito crítico dos anos 1970 permeou todas as esferas de atividades sociais. O movimento de mulheres se estabeleceu em torno das reivindicações a respeito do corpo e da recusa da "medicalização" dele. A "voz do paciente" tornou-se então audível na sociedade e tema de pesquisa em ciências sociais. 
Essas disciplinas pouco a pouco mostraram interesse em tópicos tais como gênero, corpo e emoções. As pesquisas atraíram mais ainda a atenção para a experiência privada da doença. Meu primeiro estudo nesse campo, publicado em 1973, buscava levar em conta as perspectivas individuais acerca da saúde e da doença. Meu pressuposto era o de que o que as pessoas tinham a dizer sobre esses tópicos podia ser estudado por si só. Mesmo quando as pessoas se referiam à medicina e aos médicos, não deveríamos vê-las como "dominadas" por um modelo médico todo-poderoso. Os "discursos" dos pacientes acerca da saúde e da doença narram experiências pessoais e privadas que são, no entanto, "socializadas". Eles esclarecem alguns aspectos das relações entre o indivíduo e seu grupo em contextos biográficos específicos marcados pela doença.

O crescente interesse com o pessoal, o privado e o cotidiano se deu como uma tendência geral nas ciências sociais. Norbert Elias (1978) foi um dos primeiros a indicar que essa fascinação estava relacionada ao surgimento de novos posicionamentos teóricos e à rejeição de paradigmas maiores, como o marxismo, que tinha, até então, explicado a vida coletiva e o futuro das sociedades. Mais tarde, François Dubet (1994) escreveu que, dado o "abandono da concepção clássica de sociedade como uma ordem", a sociologia agora tem como sua principal preocupação "a experiência social", algo que diz respeito "ao trabalho que cada um de nós realiza sobre nós mesmos" para ser o autor de sua própria vida. Essa exigência de trabalhar sobre si mesmo é o que caracteriza a experiência da doença. Nos anos 1980, mais e mais estudos sociológicos, baseados em dados qualitativos obtidos em entrevistas semidirecionadas, voltaram-se para a experiência da doença de pessoas leigas.

Caminho paralelo foi tomado na história. A vida privada tornava-se tema legítimo para historiadores (ARIÈS; DUBY, 1987). Enquanto isso, a história dos pacientes, por tanto tempo negligenciada, tornava-se estimulante campo de pesquisa com "documentos do eu"; em particular, as cartas que pacientes mandavam para pessoas próximas a eles ou para médicos foram sendo descobertas e examinadas.

Essa evolução nas posições intelectuais e ideológicas foi ao encontro de uma evolução no plano das patologias. Mais atenção estava sendo dada à prevalência de doenças crônicas e "degenerativas" na sociedade moderna. As doenças de longa duração, uma vez que afetam todos os aspectos da vida do paciente, requeriam um distanciamento do modelo de cuidados de saúde centrados na doença aguda. Conforme indicado por Armstrong (1984) e outros, 
os próprios médicos deveriam incluir na compreensão deles a doença crônica a vida e a "perspectiva do paciente". Nesse novo contexto, os cientistas sociais interessados no aspecto pessoal e privado da experiência da doença voltaramse para o estudo das doenças crônicas. Até certo ponto, especialmente frente aos círculos médicos, eles se tornaram os porta-vozes dos doentes crônicos que, tendo pouca visibilidade na esfera pública, ficavam fora dos meios de comunicação de massa e eram negligenciados pelas políticas de saúde.

Essas pesquisas foram uma contribuição importante para a sociologia da saúde e da doença ${ }^{3}$. Elas esclareceram vários aspectos da vida cotidiana "com ou apesar da doença" e mostraram como a doença afeta a identidade dos pacientes. Diferentemente das doenças agudas, que interrompem apenas temporariamente a vida do cotidiano, os sociólogos observaram nas experiências privadas da doença crônica evidências de uma desestabilização irreversível: a imprevisível sucessão de "dias bons" e "ruins" (CHARMAZ, 1991), a prolongada interrupção das rotinas do dia-a-dia, e a necessidade de rever os comportamentos usuais, os "posicionamentos táticos" e o conhecimento empírico que são a base da existência individual, tal como a vida do indivíduo na família e no trabalho. Estudando as várias interrupções da rotina diária, empreendemos uma investigação aprofundada da "ordem social do cotidiano", do quão frágil ela é em relação aos fatores biológicos e quão difícil é reorganizar a vida. Nesse sentido, os "fatos corporais", por tanto tempo esquecidos, encontraram lugar nas ciências sociais.

A análise dos sentidos atribuídos à experiência da doença pelas pessoas que têm de se haver com elas mostrou o quanto o corpo é importante para uma percepção da identidade. Os pesquisadores listaram as mudanças na auto-estima ocasionadas pelas doenças crônicas: sentimento de vergonha relativo ao estado de deterioração do corpo, o "estigma" sentido ao se encontrar com os outros e a sensação do paciente de uma "perda do eu (self)". Para Michael Bury (1982), uma doença duradoura leva a "uma fundamental reconsideração da biografia da pessoa e de seu conceito de si". Devido a seu conceito de "ruptura biográfica", a ênfase se deslocou na direção da dimensão temporal da experiência da doença e do trabalho "reflexivo" realizado pelos pacientes que buscam, nem sempre com sucesso, recuperar o controle de suas vidas.

Depois de vermos as contribuições positivas, vamos considerar criticamente esses estudos. Em primeiro lugar, é necessário indicar que a sociologia explorou apenas uma parte do espectro possível das carreiras relativas 
a doenças. Como Lindsay Prior (2003) recentemente indicou, a experiência da doença aguda, sobretudo durante as fases críticas, tem passado despercebida. Também negligenciamos as experiências das doenças epidêmicas, infecciosas e parasitárias nos países do Terceiro Mundo. Além disso, poucos estudos examinaram outros eventos corporais; e, quando o fizeram, trataram apenas de experiências das mulheres (menstruação, aborto e amamentação). Em segundo lugar - apesar da crescente importância da saúde nas sociedades contemporâneas e apesar da forte ênfase posta nos "estilos de vida", ênfase que está transferindo do domínio público para o privado a responsabilidade pela saúde -, os sociólogos têm realizado poucos estudos sobre o bem-estar corporal e o estar em forma. Eles estudaram as percepções da saúde e os comportamentos saudáveis, não as experiências da boa saúde do ponto de vista das pessoas em questão. Um estudo assim sistemático da saúde seria importante em si mesmo e também para uma compreensão da doença. Por exemplo, podemos supor que o vínculo muito estreito entre saúde e auto-estima piora a sensação de "perda do eu (self)" sentida pelos doentes crônicos.

Em terceiro lugar, como Janine Pierret (2003, p. 14-15) indicou em sua recente revisão desse campo, as pesquisas sobre a experiência da doença investigaram muito pouco o contexto macrossocial e não analisaram o bastante as relações entre as experiências privadas cotidianas e os fatores estruturais que as afetam. Para citar apenas um exemplo: o estigma sentido pelos doentes ou os incapacitados e o reconhecimento de seus direitos põem em evidência as opções da sociedade em seus programas sociais, bem como os laços sociais dessa sociedade. Saúde e programas de bem-estar social, assim como o financiamento do sistema assistencial e dos sistemas de seguridade social, são cruciais não apenas para as expectativas terapêuticas do paciente e para o acesso deles aos serviços de saúde, mas também para a vida e as experiências cotidianas. Porém, essas inter-relações não foram, em nossos estudos, analisadas em profundidade.

Nos anos 1990, os pesquisadores voltaram sua atenção para um novo tema, a saber, a narrativa em primeira pessoa. Mais uma vez, os sociólogos da doença estavam sendo levados por uma corrente que atravessava as ciências sociais - uma corrente de interesse na narratividade. A história da literatura tem uma tradição de diários, cartas, depoimentos pessoais e romances em torno da doença. Atualmente, essas narrativas, quer sejam espontâneas ou produzidas no contexto da pesquisa sociológica, fascinam de modo crescente os sociólogos que pesquisam sobre as doenças. Cada número de revista nesse campo traz 
agora um ou mais artigos sobre o tema - a noção de narração tornou-se um conceito-chave (HYDEN, 1997).

Não há como negar que muitos estudos científicos sobre essas narrativas são interessantes e instigantes. Os pontos de vista pessoais manifestados estão bem distantes das descrições e concepções da biomedicina. Além do mais, percebemos o quanto os cientistas sociais muitas vezes estiveram emocionalmente próximos dos pacientes cujas narrativas analisaram. No entanto, me sinto algumas vezes desconfortável com a atitude adotada por esses autores. Em primeiro lugar, a narrativa não é neutra; ela sempre se destina a alguém e busca algum objetivo subjacente. Porém, os sociólogos algumas vezes têm aceitado as narrativas por elas mesmas e, sem maiores questionamentos, considerando que elas passam uma imagem "mais verdadeira" que qualquer outro método de pesquisa poderia oferecer. $\mathrm{O}$ papel-chave atribuído à narrativa enquanto processo discursivo, apesar das referências ao corpo e ao sofrimento, tende a "desrealizar" a experiência da doença: nesses estudos, a doença se torna um "texto" com sentido, mas sem realidade ou importância material.

Para alguns pesquisadores, a principal qualidade dessas narrativas é sua dimensão moral, pois a doença é uma "ocasião moral” (FRANK, 1997) que cristaliza "lições vitais sobre o viver" (CHARMAZ, 1991). Essa perspectiva sobre a doença é diametralmente oposta à visão emergente dos estudos dos doentes crônicos em enfrentamento com a vida. A experiência pessoal da doença não é mais uma "interrupção biográfica"; ela não mais leva a uma "perda do eu (self)". Ao contrário, ela é uma autodescoberta, oferece a possibilidade de renovação e mudança, ou a oportunidade para pôr à prova a própria capacidade de "mostrar-se à altura das circunstâncias" e "ser um doente bem-sucedido". O paciente é assim apresentado como uma importante personalidade em nossa cultura individualista contemporânea. Ninguém pode negar que a doença, tal como qualquer outro evento marcante em uma vida, é uma "experiência moral" que pode ter aspectos positivos. De fato, essa idéia se adequa a uma longa tradição de interpretações religiosas da doença. Porém, é possível que todas as doenças sejam "bem-sucedidas"? Será que esse modelo de salvação pessoal por meio da doença não impõe uma pressão intensa aos pacientes que se sentem incapazes de, nesse sentido, "serem bem-sucedidos"?

Além disso, como podemos fazer com que as imagens discordantes da experiência privada e pessoal dos pacientes sejam compatíveis entre elas? Se a pesquisa sociológica deve seguir adiante, ela precisa começar levando em conta 
essa diversidade e esclarecê-la. Precisa, sobretudo, tornar-se mais reflexiva e crítica a respeito de seus próprios métodos e ações. Como os métodos de coleta de dados, o contexto da pesquisa e o comprometimento do sociólogo, enquanto porta-voz ou testemunha, influenciam as narrativas dos pacientes e, mais amplamente, o tipo de dados que somos capazes de coletar?

Contudo, esses direcionamentos da pesquisa têm pontos em comum. Ambos têm ajudado a dar visibilidade à experiência privada da doença, ao enfatizarem a dimensão individual e subjetiva do isolamento do contexto social e do domínio da vida pública coletiva. Sem dúvida, essas análises refletem uma concepção comum sobre as doenças crônicas recentes enquanto "totalmente voltadas para o interior dos indivíduos [...] e indiscernível no espaço público" (HERZLICH; PIERRET, 1987). Porém, elas não chegam a reconhecer que o que é privado não está isolado do público e do coletivo nem está separado das tendências histórico-sociais. Entretanto, a irrupção da Aids veio propor outro enquadramento interpretativo para a doença, bem como para sua experiência e suas narrativas. Dado seu caráter epidêmico e sua disseminação inicial em grupos específicos, a Aids logo se tornou um fenômeno público e coletivo.

As narrativas produzidas pelos soropositivos iam, desde o começo, bem além do domínio individual e subjetivo. Essas pessoas declaravam que elas estavam falando não apenas em nome delas mesmas, mas também em benefício de outros pacientes e dos grupos que a epidemia estava atingindo mais duramente. As narrativas expunham, portanto, testemunhos que tinham vários objetivos. Expressavam uma percepção identitária, mas o trabalho de si trazido pela experiência da doença referia-se à possibilidade de adequação da trajetória de vida individual à história do grupo. Os narradores também queriam mudar a imagem negativa da doença e lutar contra a estigmatização. A estratégia foi eficaz. No início da epidemia, quando o público apenas ouvia notícias que alardeavam o número sempre crescente de vítimas anônimas, era grande a tentação de reagir com coação. A partir de 1985, as pessoas com Aids falavam sobre suas vidas e sua situação, e eram vistas na televisão. A tendência a discriminá-los diminuiu, e os sentimentos de compaixão e solidariedade surgiram em outros grupos. Dar esse tipo de testemunho foi uma das primeiras manifestações públicas das organizações ativistas formadas para lutar contra a epidemia. Devido a tudo isso, as experiências privadas dos pacientes foram amplamente divulgadas para o público através dos meios de comunicação; e as narrativas pessoais foram parte do esforço para estimular a ação coletiva. A experiência com a Aids tornou-se, assim, um assunto público. 
Isso deu início a uma tendência que se estendeu bem além da Aids. De modo cada vez mais freqüente, a respeito de vários problemas de saúde, apareceu no espaço público um novo tipo de paciente. Associações de pacientes relativas a várias outras doenças fazem com que eles sejam ouvidos e que suas vozes tenham impacto efetivo. Suas narrativas não são apenas testemunhos. Elas podem ter a forma de queixas tal como em processos judiciais; e freqüentemente têm a forma de advertências, como em recentes "crises na saúde" (assim como com a doença da vaca louca ou a asbestose); ou mesmo na forma de acusações contra as autoridades políticas e os interesses econômicos. Em todos esses casos, formam-se grupos que, com base na experiência pessoal, reúnem pessoas.

Os pesquisadores que estudam a epidemia de Aids (eu, inclusive) nos vimos fascinados por esse surgimento repentino da experiência da doença no domínio público. O conjunto considerável das pesquisas dedicadas à Aids mostrou como os domínios privado e público da vida se sobrepõem e como a intimidade se torna coletiva e política. Enquanto cientistas sociais, não assumimos o papel de porta-vozes dos pacientes, uma vez que eles conseguiram por si próprios se fazerem ouvidos. Ao contrário, tornamo-nos seus aliados. O que nos atraiu foram tanto esse novo tipo de paciente na cena social quanto, em especial, a solidariedade e o ativismo das pessoas com Aids e suas organizações. De repente, a idéia de Parsons, de que aos doentes é negada a possibilidade de constituir um grupo, pareceu ultrapassada. Ao contrário, os pacientes agora pareciam ser o melhor exemplo para a ação e o ativismo coletivo contemporâneo. Assumimos que estávamos observando uma "mudança de paradigma": o surgimento do poder dos pacientes e a transformação radical da relação de nossa sociedade com a saúde, a medicina e a ciência. A saúde estava se tornando uma questão essencial, um tema nos noticiários (HERZLICH; PIERRET, 1988), chamando a atenção da mídia e dos políticos. Através dos ativistas organizados, a "sociedade civil" impôs sua presença nos hospitais e nos laboratórios. As relações que esses ativistas estabeleceram com a medicina e a ciência são tanto de crítica como de participação. O "ponto de vista do paciente" foi usado para criar novos direitos civis.

Porém, a epidemia de Aids tem agora 20 anos. Como avaliarmos a evolução e fazer um balanço da situação atual? É o momento de perguntar: a Aids mudou de fato as relações entre o público e o privado no campo da saúde? Terá ela mudado irreversivelmente o relacionamento das pessoas com a medicina? Nos países pobres, a Aids é agora uma vasta pandemia pondo em 
risco não apenas vidas, mas também o desenvolvimento econômico e a coesão social. Lá as vozes dos pacientes dificilmente são ouvidas. Em países ricos, a mobilização em torno da Aids, depois que os tratamentos se tornaram eficazes, diminuíram. O paciente não mais está no centro do palco. Atualmente, muitos pacientes foram mais uma vez deixados na solidão da experiência individual.

Terão os cientistas sociais superestimado as mudanças nas duas últimas décadas? Teremos deixado de reconhecer que as mudanças sociais nunca são nem homogêneas nem lineares? Não teremos acreditado muito facilmente que essas mudanças se estenderiam para outros campos da saúde? Não deveríamos ter sido mais atentos a outras evidências - por exemplo, a alguns estudos mostrando que a maioria das pessoas com Aids não pertenciam a nenhuma organização e que elas nem mesmo tinham contato umas com as outras? $\mathrm{Ou}$ ainda à evidência de que, no caso de outras doenças, poucas mudanças ocorreram no relacionamento com a medicina e na experiência com a doença? Em alguns domínios, as associações ainda são pouco visíveis, pouco eficazes e lutam pela própria existência. Os sociólogos deveriam estar atentos para essas realidades negligenciadas. Para nós, o desafio é analisar essa nova fase e, então, reexaminar a figura delineada no início deste texto.

\section{Referências}

ARIES, P.; DUBY, G. Histoire de Ia vie privée. Paris: Seuil, 1987.

ARMSTRONG, D. The patient's view. Social Science and Medicine, v. 18, n. 9, p. 737-744, 1984.

ARMSTRONG, D. The rise of surveillance medicine. Sociology of Health and IIIness, v. 17, n. 3, p. 393-440, 1995.

AUGÉ, M. Ordre biologique, ordre social: la maladie forme élémentaire de l'événement. In: AUGÉ, M.; HERZLICH, C. (Eds.). Le sens du mal. Anthropologie, histoire, sociologie de la maladie. Paris: Éditions des Archives Contemporaines, 1984. p. 35-91.

BURY, M. Chronic illness as biographical disruption. Sociology of Health and Illness, v. 4, n. 2, p. 167-182, 1982.

CHARMAZ, K. Good days, bad days: the self in chronic illness and time. New Brunswick, NJ: Rutgers University Press, 1991. 
DUBET, F. Sociologie de I'expérience. Paris: Seuil, 1994.

ELIAS, N. Zum begriff des alltags. Koiner Zeitschrift für Soziologie und Sozialpsychologie, v. 20, p.22-29, 1978.

FRANK, A. W. llIness as moral occasion: restoring agency to ill people. Health, v. 1, n. 2, p. 131-148, 1997.

HERZLICH, C. Health and iIIness, a social psychological analysis. London: Academic Press, 1973.

HERZLICH, C.; PIERRET J. Illness and self in society. Baltimore: The Johns Hopkins University Press, 1987.

HERZLICH C.; PIERRET J. Une maladie dans l'espace public: le sida dans six quotidiens français. Annales, Économies, Sociétés, Civilisations, v. 5, p. 1.109-1.134, 1988.

HYDEN, L.C. 1IIness and narrative. Sociology of health and illness, v. 19, n. 1, p. 48-69, 1997.

NIEBERK, A. A. Moral and social implications of AIDS. Africa. Journal of Medicine and Philosophy, v. 27, n. 2, p. 143-161, 2002.

PARSONS, T. Social structure and dynamic process: the case of modem medical practice. Glencoe, IL: Free Press, 1951.

PIERRET, J. The illness experience: State of knowledge and perspectives for research. Sociology of Health and Illness, Silver Anniversary Issue, p. 4-22, 2003.

PRIOR, L. Belief, knowledge and expertise: the emergence of the lay expert in medical sociology. Sociology of Health and Illness, Silver Anniversary Issue, p. 41-57, 2003. 


\section{NOTAS}

${ }^{1}$ Este artigo foi traduzido do francês para o inglês por Noal Mellot (CNRS, Paris, França) e do inglês para o português por André Rangel Rios e Marilena Corrêa (professores adjuntos do Departamento de Políticas e Instituições de Saúde do IMS/UERJ). Foi a autora quem determinou que a versão em português deveria ser não do texto em francês, mas sim do texto em inglês, pois, segundo ela, trata-se do texto mais completo. Este artigo não foi submetido anonimamente a parecerista. Sua escolha e aprovação foram feitas pelo Conselho Editorial de Physis. E-mail: publicacoes@ims.uerj.br

${ }^{2}$ Diretora de pesquisas emérita do CNRS (Centre National de Recherches Scientifiques); e diretora de estudos da EHESS (École des Hautes Études en Sciences Sociales), França. E-mail: herzlich@vjf.cnrs.fr

${ }^{3} \mathrm{O}$ número especial pelo $25^{\circ}$ aniversário da Sociology of Health and Illness traz interessante artigo de revisão de Janine Pierret (2003) sobre a pesquisa nesse campo. Essa revista inglesa já publicou diversos artigos sobre a experiência da doença - sem mencionar os artigos em outras revistas e livros.

\section{ABSTRACT}

Health and Illness on the eve of $21^{\text {st }}$ century: from private experience to the public sphere and back

Illness is known to be both the most individual and most social of all things, belonging simultaneously to the private and public domains. This article studies how the social sciences analyze the private and personal experience of illness and their discussion of the impact on the public sphere.

Key words: illness as experience; narrative; individual; society; sociology of health; collective health. 